\title{
When Football Programs Increase the Racial and Gender Diversity at Small, Private Colleges
}

\author{
Joe W. Mullins, Ph.D. \\ Reinhardt University \\ Daniel Teodorescu, Ph.D. \\ Clark Atlanta University
}

Abstract: This research examined if the addition of new small, private college football programs increased the diversity of enrollment on campus and provided opportunities for underrepresented minority students to earn a college degree. The researchers examined enrollment trends at 150 private small colleges: 50 that started new football programs between the years of 1990-2013, 50 that had existing football programs, and 50 without football programs during the same period. The study found that the percentage of small private colleges that experienced high increases in minorities and male students (5\% or higher) was higher among the colleges that started a new football program than at institutions with existing football programs or institutions without football programs. The study's findings provide valuable information for college administrators considering adding a new football program at their institution. The study also contributes new research that explores how adding a new football program impacts the diversity of student enrollment at small, private collegiate institutions. Enrollment management directors must become more aware of the need to hire diverse faculty and staff that can better relate to and serve a diverse student body. In addition, athletic leaders can approach college decision makers with information related to how the addition of a new football program will affect the diversity of student enrollment.

Keywords: diversity of enrollment, small college football, small college athletics

College football is extremely popular in the United States with over 110 million people considered as college football fans, second only to the National Football League and Major League Baseball (Sports Business Research Network, 2016). The societal culture associated with collegiate football on many campuses borders on obsession. In some large flagship institutions, football is an important aspect of campus culture with some football programs generating millions of dollars each year (Caro, 2014). For example, nine collegiate athletic departments generated over 80 million dollars through their football programs in 2015 with the University of Texas generating $\$ 121,382,436$, the most of any college football program (Sports Business Research Network, 2016). College football is the economic engine that drives collegiate athletic departments at many institutions. At the National Collegiate Athletic Associations (NCAA) Division I level, football revenues provide the financial support for all of the other collegiate sports (Dosh, 2013). 
The number of colleges and universities fielding football programs is at an all-time high (National Football Foundation, 2018). In 2016, 774 colleges and universities competed in college football (National Football Foundation, 2016). With 774 institutions sponsoring football programs, $57.5 \%$ of all four-year institutions now have a football program. Since 2011, 36 institutions have added new football programs with more expected to add football programs between 2016 and 2018 (National Football Foundation, 2016). The National Football Foundation (2016) data show that of all new football programs between 2008 and 2015, 57\% started in small institutions that compete in the National Association of Intercollegiate Athletics (NAIA) and the NCAA Division III and enroll less than 2,500 students.

The NCAA is the blanket organization for 1,100 colleges and universities located in the United States and Canada. The NCAA is a member-driven organization where colleges and universities provide representatives that serve on committees that propose and approve the policies that govern the organization (NCAA, 2016a). The NCAA divides its member institutions into three divisions based on size and mission. NCAA Division I houses 350 mostly large institutions, divided based on football participation in bowl games (NCAA, 2016b). Division I institutions provide a high level of financial support through athletic scholarships. NCAA Division II contains 300 institutions that attempt to provide student- athletes with a balance between scholarship sports and a focus on academics (NCAA, 2016b). Division III contains 444 institutions that do not provide athletic scholarships and have a primary focus on academics (NCAA, 2016b). The National Association of Intercollegiate Athletics (NAIA) is the governing body for small college athletics and has a focus on developing character within athletics. The NAIA has more than 250 member institutions with 21 athletic conferences (NAIA, 2016).

There is significant research on the role of football and its impact on large NCAA Division I college campuses. A review of recent college football feasibility studies found that Division I college and university leaders believed that adding football would provide many benefits including a sense of community on campus, an institutional identity, and increased student applications (Van Holm \& Zook, 2016). In addition, leaders believed that adding a football program would provide a complete college experience for existing students by helping students experience a sense of community, connect to alumni, increase student retention, and move commuter colleges toward becoming traditional universities (Van Holm \& Zook, 2016). Likewise, a successful college football program could have important financial implications, such as increased public funding and fundraising opportunities for the institution (Getz \& Siegfried, 2012).

Insufficient research exists, however, on the impact of adding college football on small, private college campuses. For example, small, private colleges and universities struggle to keep their doors open as they compete for students with the less expensive public universities and forprofit online colleges and universities. Small, private colleges and universities have student enrollments of 2,500 or fewer students and are heavily dependent on tuition. According to Hossler and Kalsbeek (2008), the enrollment management function is critical to the success and sustainability of small, private colleges. Beaver (2014) suggested that small colleges struggle each year to meet their enrollment goals because the cost of tuition is often two to three times the cost of public colleges. In addition, Beaver suggested that the tuition-dependent nature of small, private colleges coupled with typically moderate endowments forces these institutions to find new ways to recruit students to their campuses. As a result, many collegiate institutions add new athletic 
programs, including football, to attract new students and to retain current students. Insufficient research exists, however, that explores how the potential increased enrollment from new football programs impacts the cultural make-up of college campuses.

\section{Problem Statement and Significance of the Study}

Small, private colleges add new athletic programs to increase enrollment, generate revenue from tuition, and provide a sense of community and identity for a campus (Feezell, 2009; Kelly \& Dixon, 2011; Moltz, 2009; Weatherall, 2006). The addition of a new college football program may increase total student enrollment and also the enrollment of underrepresented students (Dalton \& Somers, 2015). Stern (2011) suggested that African American males, Latino males, and males in general lag behind the enrollment of other student groups in all colleges and universities. Stern suggested that many minority male students may not view college as an option because they are supporting a new family or live at home supporting their parents. The addition of new football programs on small, private college campuses provides an opportunity to grow male student enrollment by as much as 5\% (Beaver, 2014). Blackhurst and Auger (2008) suggested that young minority male students identify with the culture of athletics, thus making college athletics an attractive aspect of college. Young minority males see the wealth and notoriety associated with professional sports and view college athletics as a way to reach professional sports careers (Blackhurst \& Auger, 2008). Beamon (2014) suggests that young African American males often grow up with family members that push them to focus on athletics over academics. Thomas and Nasir (2013) proposed that many African American males grow up in extreme poverty and feel pressure to excel in athletics to improve their financial security. Sage and Eitzen (2016) acknowledged that using athletics as a way to get out of poverty is unlikely and a common myth within the minority community. Sage and Eitzen suggest that the percentage of athletes making a professional career is very small and should not be the focus of college athletics.

The addition of a new college football program is an important comprehensive decision for a small, private institution. College leaders are adopting football programs to promote enrollment goals. Boards of trustees, presidents, and athletic directors along with the input of faculty, staff, and students strategically decide if incorporating football is the right decision. The decision to add football student-athletes to the campus life and culture is a decision that has a plethora of ramifications for the institution. However, these ramifications are rarely the focus of administrative decision making. This research examined if the addition of new, small, private college football programs increased the diversity of enrollment on campus and provided opportunities for underrepresented minority students to earn a college degree.

Feezell (2009) suggested that the addition of football on small, private college campuses shifts the balance of power toward athletics because in many cases the majority of the student population is predominately athletes. This study makes a unique contribution to sports literature because it adds to the existing knowledge regarding the addition of new football programs, in general, as an enrollment management tool on small, private college campuses. More importantly, this study contributes new research that explored how adding a new football program impacted the diversity of student enrollment at small, private collegiate institutions. 


\section{Literature Review}

To remain fiscally stable in a turbulent economic environment, many small, private institutions utilize a tuition-driven enrollment model (Dalton \& Somers, 2015). Small, private colleges and universities must meet their enrollment goals by recruiting students and enrolling them. In the tuition-driven enrollment model, the number one resource for the university is the student. Resource dependency theory best explains why small, private colleges choose to start new collegiate football programs. Resource dependency theory states that organizations must ensure that they have access to resources from their surrounding environment to survive in their industry (Casciaro \& Piskorski, 2005). Resource dependency theory shapes the way organizational leaders perceive and adapt to external pressures that create a strain on resources (Johnson, 1995 as cited in Schulz \& Lucido, 2011). Also, resource dependency theory explains how organizations address shortages in resources through innovations and explorations into alternative resources (Schulz \& Lucido, 2011). As stated previously, small, private colleges must meet enrollment needs to stay fiscally solvent and relatively affordable. In the quest to meet enrollment needs, institutional decision makers must identify unrepresented or untapped student demographics. Dalton and Somers (2015) suggest that small, private institutions are turning to athletic programs, football in particular, to help meet enrollment needs and to tap into a scarce resource on many small, private college campuses: underrepresented minority student groups. By starting new football programs, college decision makers align their decisions with the recommendations of resource dependency theory. College decision makers understand that students are their number one resource and that competition from less expensive colleges depletes the student resource.

Small college decision makers also utilize resource dependency theory to analyze the underrepresented students on their campuses. Underrepresented student groups include ethnic minority students and students with low socioeconomic statuses (Haring-Smith, 2012). Stern (2011) suggested that African American males and males in general are a scarce resource on small college campuses. Numerous theories exist on why African American males and males in general lag behind other students in college attendance. Wang and Parker (2011) suggest that male students do not see the same benefit from college that females do, and college educated males do not feel they benefited from college as much as female students. Weaver-Hightower (2010) proposed that low male enrollment in college is a result of males falling behind in elementary and secondary education. Weaver-Hightower stated that males do not participate in college preparatory classes at the same rate as female students, and many male students grow up in a culture that fosters antiintellectualism. To improve the enrollment of African American males in college, Lynch (2015) recommended acknowledging that these students experience discrimination from educators and administrators throughout their education process and must receive early intervention in their education careers to prepare them for college.

The addition of underrepresented student groups is a critical way to improve the diversity of small, private college campuses and is beneficial to the learning process (Goodman \& Bowman, 2014). Diverse college campuses provide frequent diverse interactions for students and provide long-lasting educational benefits (Bowman, 2013). Bowman recommended that colleges and universities promote a diverse student body through the recruitment and admission of students from underrepresented student groups. The current study explored and provided a better understanding of the impact that the addition of new football programs had on the diversity of 
small, private college campuses. Resource dependency theory grounds and supports the college decision maker's decision to start new football programs and, therefore, provides the theoretical underpinnings for this research.

\section{General Diversity}

Diversity is seen as a key component of higher education with continued focus placed on making higher education accessible to all people (Aguirre \& Martinez, 2002; Butler, 2000; Wilson, 2015). Private colleges have concerns about providing access to higher education for students from socioeconomically, ethnically, racially, and geographically diverse backgrounds (Goodman \& Bowman, 2014; Stern, 2011; Talmadge, 2014). Research extols the benefits of a diverse college campus as improving teaching and learning while contributing to the mission of institutions (Fine \& Handelsman, 2010). Racially and culturally diverse campuses aid in the social and educational development of students by providing opportunities for diverse experiences in and out of the classroom (Goodman \& Bowman, 2014; Vanover \& DeBowes, 2013). For college campuses to reap the benefits of diversity, they must recruit and maintain a diverse campus (Bowman, 2013) However, current U.S. Census Bureau data indicate that colleges and universities lack gender diversity and minorities are underrepresented in higher education (Ensign \& Woods, 2014). University and sports leaders within higher education institutions must understand the importance of having a diverse campus and understand how college athletics can contribute to the diversification of college campuses.

\section{College Football and Diversity}

Diversity in higher education moderates the relationship between athletics and an increase in diversity of enrollment. The literature is clear that diversity is a key concern in higher education and such institutions are looking for ways to provide access to education for underrepresented minority student groups (Ensign \& Woods, 2014; Goodman \& Bowman, 2014; Stern, 2011; Talmadge, 2014). The literature is also clear that higher education institutions lack diversity and thus, the many benefits that a diverse campus provides students (Ensign \& Woods, 2014; Goodman \& Bowman, 2014). Diverse campuses include students from varying ethnic, racial, gender, economic, and geographic make-ups (Goodman \& Bowman, 2014; Stern, 2011; Talmadge, 2014).

The literature suggests that many colleges struggle to recruit and enroll male students (Dimaria \& Pullano, 2004; Ensign \& Woods, 2014). In addition, male students lag behind females in higher education for a myriad of reasons (Weaver-Hightower, 2010). The literature also suggests that small, private colleges are utilizing the addition of new football programs to grow male enrollment (Davis, 2011; Kelley \& Dixon, 2011; Lammers, 2010; McCloskey Jr., 2016; Pennington, 2006).

Higher education institutions are looking for ways to recruit students that contribute to the racial and ethnic diversity of campuses (Goodman \& Bowman, 2014; Stern, 2011; Talmadge, 2014). The literature suggests that university and sport leaders believed that college athletics made their campuses more racially and ethnically diverse, particularly by bringing African American male students to campus (Davis, 2011; Huffman, 2013; Pennington, 2006). The literature also 
recommends that sport and university leaders understand the dynamic of race and sport when recruiting minority student-athletes (Contreras-Godfrey, 2009; Gatmen, 2011; Hackett \& Sheridan, 2013; Harber, 2009; Locke, 2010). In addition, university and sport leaders need to recognize the potentially negative perceptions that surround revenue-generating sports and the high percentage of minority students participating in these sports (Gatmen, 2011; Hackett \& Sheridan, 2013; Huggins, 2015). The existing literature demonstrates the need for more intentional racial and ethnic diversity on college campuses and the highlights that university and sport leaders believe that athletics, football in particular, adds diversity to college campuses. However, there is no concrete data showing a relationship between the addition of football on college campuses and an increase in racial and ethnic diversity. The current research fills in the gaps in the literature by examining if the addition of a new football program on small, private college campuses lead to an increase in racial diversity.

\section{Racial and Ethnic Diversity}

Colleges and universities continue to look for ways to recruit students from economically, ethnically, racially, and geographically diverse backgrounds (Goodman \& Bowman, 2014; Stern, 2011; Talmadge, 2014). University and sports leaders continue to make decisions to add new athletic teams with the goal of bringing diverse students to campus. Huffman's (2013) research revealed that college presidents perceived athletics contributed to diversity at their institutions. Davis' (2011) study of religious institutions that added football found that school administrators believed that football contributed to their institutions' diversity by bringing students to campus from all racial demographics. Higher education leaders from numerous institutions believed that new football programs attracted African American students to campus (Pennington, 2006). University and sports leaders must understand the dynamics of race when recruiting student athletes.

The role of athletics in the lives of minority students is important for university and sports leaders to understand. Athletics attract African American males at a young age because of the prospects of a professional career and hopes of improving their lives (Gatmen, 2011; Locke, 2010). Research indicates that African American males have different athletic goals and aspirations in comparison to other ethnicities (Harber, 2009). Starting at a young age and carrying through high school, revenue-generating sports such as football and basketball draw African American males because of the possibilities of athletic scholarships (Hackett \& Sheridan, 2013). Data suggest that African American student-athletes attribute the decision to attend college and their academic success in college to their participation in athletics (Contreras-Godfrey, 2009; Huggins, 2015). Hardwick-Day's (2008) research corroborated these findings and found that minority athletes receive more NCAA Division II scholarships than Caucasian student-athletes.

University and sports leaders must understand the potentially negative perceptions associated with adding new athletic teams to aid in the diversification of campus enrollment. Gatmen's (2011) research suggested that college coaches recruit African American student athletes more than any other race. Gatmen posited that this over recruiting of African Americans, particularly at the NCAA Division I level, opens up the potential for exploitation of the studentathletes. Harper et al.'s (2013) research indicated that in NCAA Division I, African American male student-athletes represent a small percentage of graduating students but a large percentage of total 
student-athletes. Huggins (2015) presented data from 2009-2010 showing that only $10 \%$ of African Americans earned a bachelor's degree and $60 \%$ of those graduates were female. In addition, Hackett and Sheridan's (2013) research indicated that 25\%-35\% of all African American athletes that are eligible for an athletic scholarship could not qualify academically. The existing data focus exclusively on NCAA Division I and II, thus supporting the need for the current study.

\section{Gender Diversity and Football}

College athletics play an important role for higher education institutions by aiding in the recruitment of under-represented student groups (Getz \& Siegfried, 2012). Dimaria and Pullano (2004) posited that gender equity is a legitimate issue facing colleges and universities. Many colleges and universities struggle in the enrollment of male students. The gap between female and male enrollment continues to grow with females enrolling at a ratio of 2:1 to male students. (Dimaria \& Pullano, 2004; Ensign \& Woods, 2014). Weaver-Hightower (2010) suggested that the male perspective is important on college campuses and that there are legitimate reasons why male college enrollment lags behind female enrollment. He proposed that the lack of male enrollment in college stems from a lack of college preparation starting in elementary school and carrying through high school. In addition, he suggested that many males have a negative view of intellectualism and view colleges as a place to promote the feminization of males. Lastly, WeaverHightower acknowledged that college athletics is one legitimate avenue that institutions can utilize to attract male students.

Small, private colleges are adding football programs as a way to grow their male enrollment (Dalton \& Somers, 2015; Davis, 2011; Feezell, 2009; McCloskey Jr., 2016; Pennington, 2006; Suggs, 2004). Higher education leaders understand that the addition of a football program will add one hundred or more male students to their campuses and research says that the addition of a new football program will boost total male applications for athletes and non-athletes (Kelley \& Dixon, 2011; Pennington, 2006). Because of the increasing numbers of institutions adding new football programs, there are success stories from many institutions that experienced substantial growth in their male student enrollment. The University of Mary Hardin-Baylor, for instance, grew male enrollment from $32 \%$ to $40 \%$ in the first year after the addition of football (Pennington, 2006). Lake Erie College also improved its male to female ratio from $73 \%$ female and $27 \%$ male to $60 \%$ female and $40 \%$ male through the addition of football (Lammers, 2010). McCloskey Jr. (2016) noted that Misericordia University and Stevenson University improved their male enrollment from $29 \%$ to $44 \%$ and $34 \%$ to $43 \%$ respectively after the addition of football. Davis' (2011) research indicated that faith-based liberal arts institutions also benefited from the addition of new football programs with institutions adding between 85-130 male students.

With the addition of new football programs, athletic leaders must ensure that their institutions comply with Title IX and that they do not create a gender imbalance skewed toward male enrollment. Beaver's (2014) research on enrollment of 80 NCAA Division III institutions produced data showing that none of the schools with football programs had more female athletes than males and that there was an average of 104 more males athletes than female athletes. Feezell (2009) suggested that schools with new football programs would need to add more female sports to stay in compliance with Title IX. In addition, Feezell's research suggested that the addition of football produced mixed results on gender balancing with some schools showing less than a $10 \%$ 
increase in male enrollment. The existing research on how the addition of football affects gender diversity on college campuses comes primarily from single institution case studies, thus supporting the need for a multi-institution study.

\section{Theoretical Framework}

To remain fiscally stable in an environment of economic uncertainty and increasing competition, many small, private institutions utilize a tuition-driven enrollment model (Dalton \& Somers, 2015). Small, private colleges and universities must meet their enrollment needs by recruiting students and enrolling them. In the tuition-driven enrollment model, the most critical resource for the university is the student. Resource dependency theory best explains why small, private colleges choose to start new collegiate football programs as part of their student enrollment strategy. In their 1978 (reprinted in 2003) seminal work The External Control of Organizations: A Resource Dependence Perspective, Pfeffer and Salancik (2003) formalized resource dependency theory. Pfeffer and Salancik (2003) proposed that organizations need resources to function effectively and efficiently. To acquire resources, organizations must depend on their external environment, which may be unclear and challenging (Pfeffer \& Salancik, 2003). Furthermore, most organizations are not self-sufficient and must acquire external resources to survive (Black, 2001). Resource dependency theory explains how organizations address shortages in resources through innovations and explorations into alternative resources (Pfeffer \& Salancik, 2003; Schulz \& Lucido, 2011). In the context of higher education, resource dependency theory explains how colleges and university enrollment managers respond to the changing environment of higher education (Black, 2001; Pfeffer \& Salancik, 2003). As stated previously, small private colleges must meet enrollment goals to stay fiscally solvent and relatively affordable. In the quest to meet enrollment these goals, institutional leaders must identify unrepresented or untapped student demographics. Resource dependency theory accounts for the fact that small, private institutions are highly dependent on tuition revenue and that revenue derived from student enrollment is an important resource for small institutions (Black, 2001). The addition of new athletic teams has the potential to add new student enrollment and additional tuition revenue, thus helping institutions acquire a much-needed resource.

Institutional leaders at small private institutions are turning to athletic programs, football in particular, to help meet enrollment needs and to tap into a scarce resource on many small private college campuses, i.e., the male student (Dalton \& Sommers, 2015). Resource dependency theory states that college enrollment managers must examine what resources are scarce on a particular campus (Black, 2001). For many small, private colleges, student enrollment numbers and tuition resulting from the increased number of students generated by starting a new football program can potentially help these colleges acquire male students that many institutions need to balance their enrollment (Gardiner, 2010; Getz \& Siegfried, 2012; Lammers, 2010; McCloskey Jr., 2016; Pennington, 2006). Lammers (2010) found that the addition of football and other athletic programs at Lake Erie College helped bring the male/female enrollment percentage in line with national averages. Like Lammers, Getz and Siegfried (2012) found that Shenandoah University revived its football program to attract more males to campus.

Small college institutional leaders utilize resource dependency theory to analyze the underrepresented students on their campuses. Breneman (1994) suggested resource dependency 
theory helps college leaders identify if their campus lacks enrollment diversity. Stern (2011) suggested that African American males are a scarce resource on small college campuses. The addition of a football program aligns with the resource dependency theory because it explains how colleges can recruit more racially diverse students to campus using innovative tactics to tap into that particular resource. This research examined if adding a new football program to an athletic department increased the diversity of enrollment on small, private college campuses. The existing research highlights both positive and negative enrollment trends on small college campuses that start new football programs. The current research aimed to contribute to the existing literature regarding the relationship between starting a new football program and student enrollment. However, the larger goal of the research was to explore in a broader context how starting a new football program on a college campus affected the diversity of student enrollment. Resource dependency theory helps explain why college leaders may choose to add new football programs to athletic departments. Resource dependency theory thus served as an appropriate theoretical framework for this investigation.

\section{Research Questions}

Small, private colleges and universities continue to add new athletic teams to grow student enrollment. In particular, institutions add new football programs to increase total enrollment, male enrollment, and enrollment of underrepresented student populations (Dalton \& Somers, 2015). Small, private colleges and universities are taking advantage of the fact that students often choose small colleges to continue their playing career (Bandre, 2011; Beaver, 2014). It is our opinion that college decision makers are starting football programs without considering how this addition will affect the diversity of student enrollment on campus. The purpose of this quantitative study was to explore if the addition of a new college football program resulted in an increase in the diversity of student enrollment at small, private institutions. Specifically, two research questions guided this quantitative

study:

R1: To what extent does the addition of a football program result in increased enrollment of non-Caucasian students at small, private institutions compared to institutions not initiating a program?

R2: To what extent does the addition of a football program result in increased enrollment of male students at small, private institutions compared to institutions not initiating a football program?

\section{Methods}

The current study utilized a nonexperimental quantitative research design that was explanatory and retrospective in nature. According to Belli (2009), nonexperimental research involves the study of variables as they exist instead of manipulating the variables. The current study is also explanatory (a) because it aims to elucidate how a phenomenon worked, i.e., the addition of football on a small, private college campus, and (b) because hypotheses were present to test a theory about the phenomenon (Belli, 2009). This study is also classified as retrospective because it looks back in time using existing data to explain or explore a phenomenon (Belli, 2009). 
An explanatory retrospective research design was appropriate for the current study because past data were available to explain and test the research hypotheses.

\section{Study Population and Sample Selection}

The basis of the current research came from the observation that between 1990 and 2013 many small, private colleges and universities added new football programs. Data from numerous sources validated the claim that between 1990 and 2013, many small, private universities added new football programs (D3 Football, 2017; Dalton, 2011; NAIA, 2017; NCAA, 2017; NCAA Football, 2014; National Football Foundation, 2018). The available data suggested that approximately 65 small, private institutions added football during the defined timeframe (D3 Football, 2017; Dalton, 2011; NAIA, 2017; National Football Foundation, 2018; NCAA, 2017; NCAA Football, 2014). To be included into this study, institutions had to meet three criteria: be classified as private, enroll les than 2,500 students at the time of the addition of football, and belong to the NCAA Division III or NAIA at the time of the addition of football. The comparison groups were selected randomly from a list of institutions that were classified as private, enrolled less than 2,500 students, and belonged to NCAA Division III or NAIA. Data from NCAA Division III and NAIA member directories and the Integrated Postsecondary Education Data System (IPEDS) were used in the identification and selection of qualifying institutions for each group (NAIA, 2017; National Center for Educational Statistics, 2017a; NCAA, 2017).

\section{Instrumentation}

The current study utilized data from the National Center for Educational Statistics (NCES) (2017a) Integrated Postsecondary Education Data System (IPEDS). The NCES uses IPEDS to collect data annually from higher education institutions to describe the state of higher education (NCES, 2017b). Specifically, the study utilized IPEDS fall enrollment and student financial aid data for the years 1990-2013 using the following variables:

\section{Independent Variables}

\section{Presence or Absence of a Football Program (1990-2013)}

The researchers divided the institutions examined into three research groups: institutions that started football programs during the specified period, institutions with existing football programs, and institutions without football programs. It should be noted that the year the football program was launched varied across institutions.

\section{Dependent Variables}

\section{Percentage of Non-Caucasian Student Enrollment (1990-2013)}

Percentage of minority student enrollment based on Annual Fall Enrollment Survey totals from IPEDS. 


\section{Percentage of Male Student Enrollment (1990-2013)}

\section{IPEDS.}

Percentage of male student enrollment based on Annual Fall Enrollment Survey totals from

\section{Validity and Reliability}

IPEDS collects higher education institutional data from postsecondary institutions throughout the United States and in other U.S. jurisdictions (Ginder et al., 2016). Because the Higher Education Act of 1965 and other higher education amendments require submission of data to IPEDS to receive federal financial aid, the response rate is nearly 100\% (Ginder et al., 2016). During each year of IPEDS data submission, a representative from each institution enters data into IPEDS protected system (Ginder et al., 2016). IPEDS compares each year's data against the previous year's data for consistency and automatically checks entries for missing data or data that are outside the expected range based on the previous year's submissions (Ginder et al., 2016). Institutions have the ability to explain abnormal data and IPEDS staff follow up with institutions about abnormal data to correct potential errors (Ginder et al., 2016).

\section{Data Collection Procedures}

This study utilized a multi-step process to collect data. Step one involved mining data using the IPEDS database. For the current study, the selection criteria for the institutions in the sample included the following institutional characteristics: U.S. only, private not-for-profit four- year and above, primarily baccalaureate or above, and enrollment of 2,500 students or less. IPEDS produced a list of institutions that fit the search criteria starting with the year 2015. After creation of the list of appropriate institutions, the researchers extracted enrollment data by race/ethnicity and gender.

IPEDS allows users to add subsequent years using the same search characteristics. By starting at 2015 and working backward, IPEDS kept the list of institutions consistent from year to year, thus making data mining manageable. The result of step one was the creation of 13-18 years of institutional data with each year's data in a separate spreadsheet.

Step two in the data collection process involved consolidating data and creating new variables. As stated previously, step one produced a separate spreadsheet for each year's data. For step two, all spreadsheets were combined into one starting with the year 2015. Because IPEDS did not create the exact variables needed for the study, formulas were used to create percentage of non-Caucasian students and percentage of male students. In addition, a variable was created to measure the percentage change in male and non-Caucasian enrollment before and after the addition of a new football program. 
Step three in data collection involved identifying the institutions needed for each of the three research groups:

- Group 1: the football addition group comprising institutions that had existing football programs between the years 1990-2013 (comparison group)

- Group 2: the institutions that did not have football programs during the years 19902013 (comparison group)

- Group 3: the football addition group comprising institutions that introduced football programs between the years 1990-2013

Existing data from several sources identified institutions that added football between the years 1990-2013 and the year that they added football (D3 Football, 2017; Dalton, 2011; NAIA, 2017; National Football Foundation, 2018; NCAA, 2017; NCAA Football, 2014). A key aspect of the current study involved identifying the exact year that institutions enrolled new football studentathletes. For some institutions, the first football student-athletes arrived the same year that the institution played its first game. For other institutions, the first football student-athletes arrived a year before the first football contest. The identification of the correct year that the first football student-athletes arrived was critical in producing the most accurate data.

Step four involved forming the two comparison groups for the study. The first comparison group comprised the same number of schools as the football addition group and included institutions that had existing football programs between the years 1990-2013. Group 2 comprised institutions that did not have football programs during the years 1990-2013 and had the same number of schools as the football addition group and group one. Existing data from the multiple sources were used to form a master list of schools for each group and random sampling was utilized to obtain representative numbers of schools for each group (D3 Football, 2017; Dalton, 2011; NAIA, 2017; National Football Foundation, 2018; NCAA, 2017; NCAA Football, 2014).

The final step in the data collection involved finalizing the three groups of institutions for comparison. Fifty small, private institutions with existing football programs between the years of 1990-2013 and 50 institutions without football programs between the years of 1990-2013 served as comparison groups (see Table 1). The comparison groups were necessary to determine if any observed changes in minority enrollment resulting from the addition of a new football program were statistically different from changes in minority enrollment observed in institutions with existing football programs and institutions without football programs. 


\section{Table 1}

Final Research Groups

\begin{tabular}{|c|c|c|c|}
\hline Groups & Group 1 & Group 2 & Group 3 \\
\hline & $\begin{array}{l}50 \text { small, private } \\
\text { institutions that } \\
\text { added new } \\
\text { football } \\
\text { programs } \\
\text { between the } \\
\text { years of 1990- } \\
2013\end{array}$ & $\begin{array}{l}50 \text { small, private } \\
\text { institutions with } \\
\text { existing football } \\
\text { programs between the } \\
\text { years of } 1990-2013\end{array}$ & $\begin{array}{l}50 \text { small, private } \\
\text { institutions without } \\
\text { football programs } \\
\text { between the years of } \\
1990-2013\end{array}$ \\
\hline
\end{tabular}

\section{Characteristics of the Sample}

The institutions in the research sample were 150 small, private institutions with student enrollments of 2,500 students or less. All sampled institutions belonged to the NCAA Division III or NAIA at some point during the years of 1990-2013 (see Table 2). In addition, they represented all regions of the U.S. as defined by Bureau of Economic Analysis (BEA) (see Table 2). Because the study encompasses institutions from all regions of the country, the data were representative of small, private institutions throughout the U.S.

\section{Table 2}

Distribution of Colleges by Governing Body Association and Region

Frequency

Governing Body

NAIA

NCAA Division III

58

92
Region

Far West

Great Lakes

Mid-East

New England

Plains

Rocky Mountains

Southeast

Southwest

Total
6

26

27

11

24

2

46

8

150
Percent

38.7

61.3

17.3

18.0

7.3

16.0

1.3

30.7

5.3

100.0 


\section{Research Timeframe}

Table 3 shows the research timeframe utilized for each of the three research groups. Group one consisted of the schools that added new football programs. For this group, enrollment was measured as an average of the three years prior to the introduction of a new football program and the three years after the introduction of a new football program (see Table 3 ). The difference was measured in the change in enrollment between the pre- and post-football years and coded accordingly. For groups two and three, the institutions with existing football programs and without football programs, the three-year average enrollment was measured in the year with the most frequent additions of new football programs (see Table 3). Figure 1 shows that the years of 1999, 2000, 2006, 2008, 2011, and 2012 were the most frequent years for the addition of a new football program. For the purpose of this research, 2006 was chosen as the benchmark year for research groups two and three (see Table 3).

\section{Table 3}

Research Timeframe

\begin{tabular}{llll}
\hline Groups & Group 1 & Group 2 & Group 3 \\
\hline $\begin{array}{l}\text { Three-year } \\
\text { average pre- } \\
\text { football three- } \\
\text { year average }\end{array}$ & $\begin{array}{l}\text { Three-year pre- } \\
\text { average and three- } \\
\text { year post-average }\end{array}$ & $\begin{array}{l}\text { Three-year pre- } \\
\text { average and three- } \\
\text { year post-average }\end{array}$ \\
$\begin{array}{lll}\text { Benchmark } \\
\text { Year: Varies }\end{array}$ & Benchmark Year: & Benchmark Year: \\
& & 2006 \\
\hline
\end{tabular}




\section{Figure 1}

\section{Year of Football Addition}

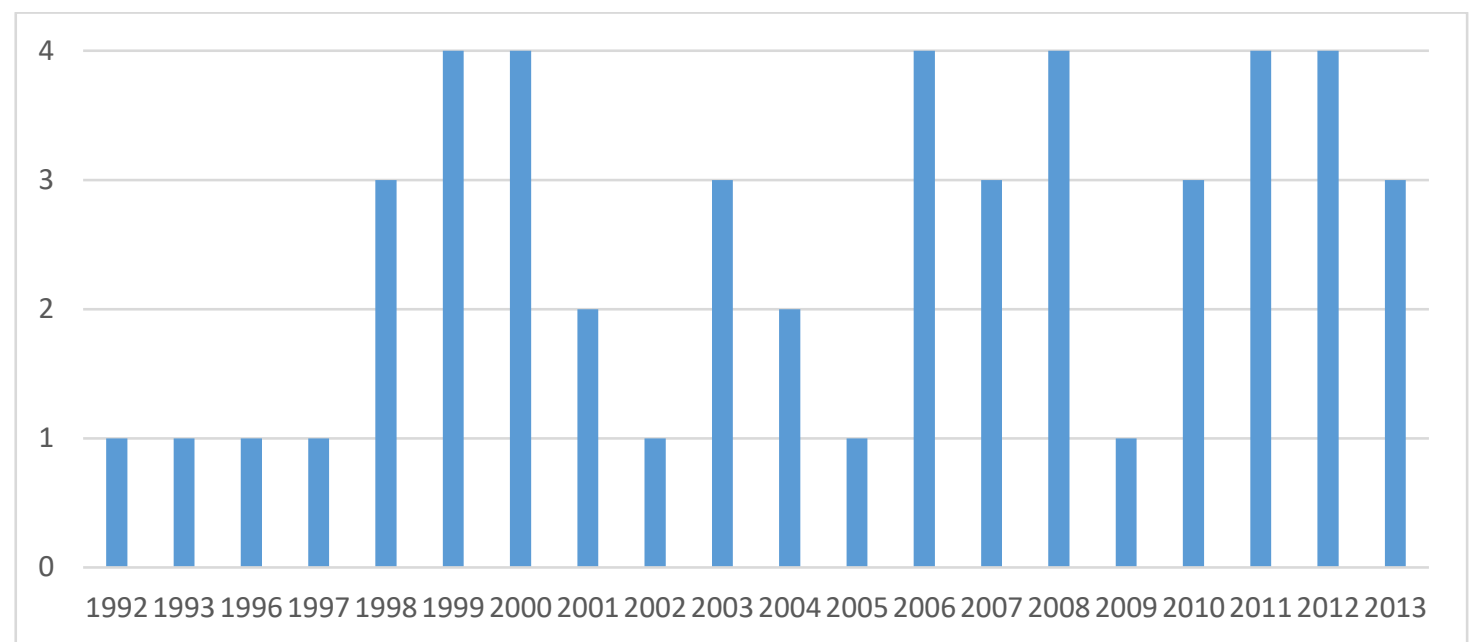

Results

\section{Minority Enrollment}

Table 4 presents the descriptive data on minority enrollment for small, private institutions that added new football programs between the years of 1990-2013. The institutions that added new football programs were the primary research group in the study. Minority enrollment was measured as an average of the three years prior to the addition of a new football program and three years following the introduction of a new football program. The data were represented as the percentage of the institution's total student enrollment that was non-Caucasian. Table 4 shows that the 50 small, private institutions that added new football programs had an average minority representation of $14.8 \%(M=14.8)$ for the three years prior to the introduction of a new football program. The same institutions had an average minority representation of $19.5 \%(M=19.5)$ for the three years following the introduction of a new football program (see Table 4). The small, private institutions that added new football programs experienced an average change in minority enrollment between the three years prior to adding football and the three years after adding football of $4.6 \%(M=4.6)$ (see Table 4$)$. 


\section{Table 4}

Descriptive Statistics for \% Minority Enrollment Group 1

\begin{tabular}{lccc} 
& N & Mean & Std. Deviation \\
\hline $\begin{array}{l}\text { Post - Football Average Minority } \\
\text { Enrollment }\end{array}$ & 50 & 19.5 & 13.2 \\
$\begin{array}{l}\text { Pre - Football Average Minority } \\
\text { Enrollment }\end{array}$ & 50 & 14.8 & 10.3 \\
$\begin{array}{l}\text { Pre/Post - Football Change in Minority } \\
\text { Enrollment }\end{array}$ & 50 & 4.6 & 5.6 \\
\hline
\end{tabular}

Note. Institutions that added new football programs.

Table 5 presents the descriptive statistics for minority enrollments at institutions in the two comparison groups. The table reveals that the 100 small, private institutions with existing football programs and without existing football program had an average minority enrollment of $13.4 \%(M$ $=13.4$ ) for the three years prior to the benchmark year of 2006. The same institutions had an average minority enrollment of $14.3 \%(M=14.3)$ for the three years following the benchmark year of 2006 (see Table 5). The small, private institutions with and without existing football programs experienced an average change in minority enrollment between the three years before the benchmark year of 2006 and the three years after the benchmark year 2006 of $.88 \%(M=.88)$ (see Table 5).

\section{Table 5}

Descriptive Statistics for $2006 \%$ Minority Enrollment Groups 2 and 3

\begin{tabular}{llll} 
& N & Mean & Std. Deviation \\
\hline $\begin{array}{l}\text { Post - 2006 Average Minority } \\
\begin{array}{l}\text { Enrollment } \\
\text { Pre - 2006 Average Minority Enrollment }\end{array}\end{array}$ & 100 & 14.3 & 14.2 \\
$\begin{array}{l}\text { Pre/Post - 2006 Change in Minority } \\
\text { Enrollment }\end{array}$ & 100 & 13.4 & 14.4 \\
\end{tabular}

Note. Institutions with existing football programs and institutions without football programs. 
Table 6 shows the cross-tabulation of research group by magnitude of change in minority enrollment and the results of a chi-square test of independence for minority enrollment. Colleges were grouped into three categories based on the magnitude and direction of change in minority enrollments: (a) institutions that experienced a 5\% or higher increase in minority enrollment, (b) institutions that experienced no significant change in minority enrollment (lower than 5 percent change), and (c) institutions that experienced a 5\% or higher decrease in minority enrollment.

Table 6 shows that $38 \%$ of institutions that added new football programs experienced growth of $5 \%$ or more in minority student representation, and only $2 \%$ of institutions with existing football programs and $2 \%$ of institutions without football programs experienced an increase of similar magnitude. A chi-square test of independence was performed and found a significant relationship between the addition of a new football program and change in minority representation, $\chi^{2}(4, N=150)=37.42, p<.001$, Cramer's $V=.35$. The Cramer's $V$ score of .35 indicated a medium effect size and a moderate association between the addition of a new football program and the change in minority enrollment (Rea \& Parker, 1992; Salkind, 2014).

\section{Table 6}

Cross-Tabulation of Addition of Football by Change in Minorities Enrollment

\begin{tabular}{lllll}
\hline & \multicolumn{3}{c}{ Change in \% Minorities } & \\
\cline { 2 - 4 } College Group & $\begin{array}{l}1(+5 \% \text { of } \\
\text { higher })\end{array}$ & $\begin{array}{l}2(-4.99 \% \text { to } \\
4.99 \%)\end{array}$ & $\begin{array}{l}3(-5 \% \text { or } \\
\text { lower })\end{array}$ & $\mathrm{N}$ \\
\hline Added Football & $38.0 \%$ & $62.0 \%$ & $0.0 \%$ & 50 \\
No Football & $2.0 \%$ & $96.0 \%$ & $2.0 \%$ & 50 \\
Existing Football & $2.0 \%$ & $98.0 \%$ & $0.0 \%$ & 50 \\
\hline$\chi^{2}(4, N=150)=37.42, p<.001$, Cramer's $V=.35$.
\end{tabular}

\section{Male Enrollment}

Table 7 presents the descriptive statistics for male enrollments at small, private institutions that added new football programs between the years of 1990-2013. The table shows that the 50 small, private institutions that added new football programs had an average male enrollment of $39.1 \%(M=39.1)$ for the three years prior to the introduction of a new football program. The same institutions had an average male enrollment of $42.7 \%(M=42.7)$ for the three years following the introduction of a new football program (see Table 7). Thus, this group of institutions experienced an average increase in male enrollment between the three years before adding football and the three years after adding football of 3.6 percentage points $(M=3.6)$ (see Table 7). 


\section{Table 7}

Descriptive Statistics \% Male Enrollment - Group 1

\begin{tabular}{lccc} 
& $\mathrm{N}$ & Mean & Std. Deviation \\
\hline $\begin{array}{l}\text { Post - Football Average Male } \\
\text { Enrollment }\end{array}$ & 50 & 42.7 & 6.8 \\
$\begin{array}{l}\text { Pre - Football Average Male } \\
\begin{array}{l}\text { Enrollment } \\
\text { Pre/Post Football Change in } \\
\text { Male Enrollment }\end{array}\end{array}$ & 50 & 39.1 & 7.4 \\
\end{tabular}

Note. Institutions that added new football programs.

Table 8 presents the descriptive statistics for male enrollments at institution in the two comparison groups. Table 8 shows that the 100 small, private institutions with and without an existing football program had an average male enrollment of $37.6 \%(M=37.6)$ for the three years prior to the benchmark year of 2006. The same institutions had an average male enrollment of $38.7 \%(M=38.7)$ for the three years following the benchmark year (see Table 8$)$. The small, private institutions with and without football programs experienced an average change in male enrollment between the three years before the benchmark year of 2006 and the three years after the benchmark year 2006 of one percentage point $(M=1.10)$ (see Table 8).

\section{Table 8}

Descriptive Statistics $2006 \%$ Male Enrollment - Groups 2 and 3

\begin{tabular}{lccc} 
& $\mathrm{N}$ & Mean & Std. Deviation \\
\hline $\begin{array}{l}\text { Post - 2006 Average Male } \\
\text { Enrollment }\end{array}$ & 100 & 38.7 & 13.9 \\
$\begin{array}{l}\text { Pre - 2006 Average Male } \\
\text { Enrollment }\end{array}$ & 100 & 37.6 & 13.1 \\
$\begin{array}{l}\text { Pre/Post 2006 Change in Male } \\
\text { Enrollment }\end{array}$ & 100 & 1.1 & 7.2 \\
\hline
\end{tabular}

Note. Institutions with existing football programs and institutions without football programs.

Table 9 shows the cross-tabulation of research group by change in male enrollments as well as results of a chi-square test of independence. The table shows that $32 \%$ of institutions that 
added new football programs experienced a significant growth (5 percentage points or more) in male representation while $8 \%$ of institutions with existing football programs and $6 \%$ of institutions without football programs experienced similar growth in male enrollment. A chisquare test of independence was performed and found a significant relationship between research group and the magnitude of change in male representation, $\chi^{2}(4, N=150)=20.02, p<.001$, Cramer's $\mathrm{V}=.25$. The Cramer's V score of .25 indicates a medium effect size and a moderate association between the addition of a new football program and change in male representation.

\section{Table 9}

Cross-Tabulation of Addition of Football by Change in Male Enrollment

\begin{tabular}{lllll}
\hline & \multicolumn{3}{l}{ Change in \% Males } & \\
\cline { 2 - 4 } $\begin{array}{l}1(+5 \% \text { or } \\
\text { higher })\end{array}$ & $\begin{array}{l}2(-4.99 \% \\
\text { to } 4.99 \%)\end{array}$ & $\begin{array}{l}3(-5 \% \text { or } \\
\text { lower })\end{array}$ & $\mathrm{N}$ \\
\hline Added Football & $32.0 \%$ & $64.0 \%$ & $4.0 \%$ & 50 \\
No Football & $6.0 \%$ & $94.0 \%$ & $6.0 \%$ & 50 \\
Existing Football & $15.3 \%$ & $81.3 \%$ & $3.3 \%$ & 50 \\
\hline$\chi^{2}(4, N=150)=$ & $20.02, p<.001$, Cramer's V $=.25$ &
\end{tabular}

\section{Discussion and Interpretation}

Higher education institutions are under continued pressure to make higher education accessible to all people (Aguirre \& Martinez, 2002; Butler, 2000; Wilson, 2015). Diverse college campuses provide students with a better learning experience and contribute to the mission of higher education (Fine \& Handelsman, 2010). Research suggests that colleges and universities lack diversity and fall short of providing underrepresented students with access to higher education (Ensign \& Woods, 2014). In particular, private colleges and universities struggle to provide access to higher education to students from racially, socioeconomically, and geographically diverse backgrounds (Goodman \& Bowman, 2014; Stern, 2011; Talmadge, 2014). College and university leaders are adding new athletic programs, football in particular, as a method to grow student enrollment and enrollment of underrepresented student groups (Beaver, 2014; Dalton, 2011; Dalton \& Somers, 2015; Davis, 2011; Dimaria \& Pullano, 2004). The findings of this study show that the addition of new football programs on small, private college campuses does lead to an increase in the enrollment of certain underrepresented student groups. 


\section{Minority Enrollment}

The current study found that small, private institutions that added new football programs experienced a higher increase in minority enrollment compared to small, private institutions with existing football programs and small, private institutions without football programs. University and sport leaders continue to add new athletic teams with the goal of bringing new students and more diverse students to their campuses. Davis (2011) and Huffman (2013) found that college administrators believed that college athletics, football in particular, added to the diversity of their campus by bringing students from various racial and ethnic backgrounds. The Davis and Huffman studies only reported the perceptions or beliefs of college administrators and offered no empirical evidence that the addition of a college athletic program actually increases minority enrollment. The current study supported the perceptions and beliefs posited in the Davis and Huffman studies.

A substantial part of the existing literature pertaining to racial diversity and college football deals with the attraction that minority students, African American males in particular, have to high profile sports such as college football. Research suggests that African American males are drawn to college football because of college scholarships and aspirations for a professional career in football (Gatmen, 2011; Hackett \& Sheridan, 2013; Harber, 2009; Locke, 2010). Furthermore, data suggests that participation in college athletics is a driving factor for African American students' decision to attend college and their academic success once enrolled in college (Contreras-Godfrey, 2009; Huggins, 2015). The results of the current study showed that university and sport leaders can use the addition of a new football program as an enrollment tool to grow the minority enrollment on their campuses and provide opportunities for minority students to earn a college degree.

While the findings of the current study demonstrated that the addition of a new football program can increase minority enrollment on small, private college campuses, the study did not focus on the potentially negative perceptions associated with the over recruitment and over representation of minority students in revenue-generating sports. Previous research showed that minority athletes made up a substantial percentage of NCAA Division I student athletes while representing a small portion of overall students who receive a college degree (Hackett \& Sheridan, 2013; Harper et al.; Huggins, 2015). University and sport leaders at small, private colleges and universities must use the addition of new football programs as a way to provide opportunities for minority students to attend college and graduate with a college degree.

\section{Male Enrollment}

The current study found that small, private institutions that added new football programs experienced higher increases in male student enrollment compared to small, private institutions with existing football programs and small, private institutions without football programs. Gender equity and the lack of male participation is a legitimate concern for higher education institutions and their leaders (Dimaria \& Pullano, 2004; Ensign \& Woods, 2014). While existing research provides explanations for the underrepresentation of males in higher education and the need for the male perspective on college campuses, higher education leaders must still find ways to increase male enrollment at their institutions (Weaver-Hightower, 2010). The current study's findings indicate that adding a football program could be an effective method for increasing male enrollment on small, private college campuses. 
Research suggests that small, private college campuses have added new football programs to bolster male enrollment (Dalton, 2011; Dalton \& Somers, 2015; Davis, 2011; Feezell, 2009; McCloskey Jr., 2016; Pennington, 2006; Suggs, 2004). The limited data on how new football programs impact male enrollment suggested that colleges and universities could expect to experience a male enrollment increase of 85 to 130 students during their first year of having a new football program (Davis, 2011; Kelley \& Dixon, 2011). Feezell (2009) concluded that the addition of a new football program showed mixed results in gender balancing, with some schools experiencing less than a $10 \%$ increase in male enrollment. However, previous research only reports increases in male enrollment without a benchmark for comparison. The current study concluded that $32 \%$ of institutions that added new football programs experienced a five percent increase or more in male enrollment compared to $16 \%$ among institutions with existing football programs and six percent among institutions without football programs. Feezell's study downplayed the significance of any increase in male enrollment that was not $10 \%$ or more. Yet, a five percent or higher increase in male representation is significant for small, private institutions that have total enrollment of 2,500 students or less. The current study's findings show that the addition of a new football program on small, private college campuses can aid in the balancing enrollment by gender. However, the current study does not account for how football impacts male enrollment long term at an institution. The research is clear that football can be an effective tool for increasing male enrollment, but higher education and sport leaders that add new football programs will have to develop additional enrollment strategies to further grow male enrollment and retention after the addition of a new football program.

\section{Implications for Practice}

The current study contributes to the existing knowledge on the relationship between college athletics, football in particular, and student enrollment, while providing concrete data on the relationship between football and student enrollment and diversity of student enrollment. The current study's findings confirmed what other scholars believed: that the addition of a new football program will increase minority student enrollment on small, private college campuses.

The current study's theoretical framework was based on resource dependency theory. Resource dependency theory in part states that organizations need resources to survive and must address shortages in resources through innovative practices and examination of alternative resources (Pfeffer \& Salancik, 2003; Schulz \& Lucido, 2011). In the fabric of higher education, small, private colleges and universities view students as their number one resource, and they spend considerable effort and money trying to recruit and enroll students at their institution. Decision makers at small, private institutions must tap into underrepresented student groups not common to their institutions in order to continue to grow their student enrollment. Following the tenets of resource dependency theory, small, private college decision makers have started new athletic programs, football in particular, to tap into new resources in the form of students. The current study's findings indicate that the addition of a new football program on small, private college campuses can help the institutions increase their numbers of minority students and male students. These student groups represent new resources for the university and can help the institution continue to function while providing much needed diversity to many small, private college campuses. 
The current study's findings are valuable to practitioners in higher education and college athletics. For practitioners in higher education such as enrollment officers and college administrators responsible for enrollment management, the current study provides insight into how enrollment will change after starting a new football program. Because the addition of a new football program will increase diversity, minority diversity in particular, higher education administrators must become more aware of the need to hire diverse faculty and staff that can better relate to and serve a diverse study body. For practitioners in college athletics, the current study's findings provide valuable information for athletic directors considering adding a new football program at their institution. Athletic leaders can approach college and university decision makers with information related to how the addition of a new football program will affect the diversity of student enrollment, which will allow for better decisions regarding the addition of a new football program.

The addition of a new football program on a small, private college campus will stress the resources of an institution and fundamentally change the demographic makeup of the student population. University and sport leaders must be prepared to offer more classes, hire more faculty, and provide more academic resources such as academic tutors. In addition, adding a new football program may place stress on other institutional departments such as housing, food service, financial aid, and public safety. University and sport leaders should also be prepared to offer diversity and sexual violence training on campus. In addition, small, private college leaders must ensure that their institutions do not fall into a common practice found at large NCAA Division I institutions: over-recruiting minority students into college sports and not graduating those students (Gatmen, 2011; Harper et al., 2013).

\section{Implications for Research}

The main contribution of the current study is that it provided quantitative data findings that contributed to existing literature that was largely based on qualitative research. The existing literature provided many narrative accounts that university and sport leaders at a select number of institutions believed that the addition of a new football program led to the diversification of their campuses. The current study provided quantitative evidence that both confirmed and contradicted existing literature and was based on a larger sample of small, private institutions.

The current study's findings make a unique contribution to the existing knowledge relating to how the addition of athletic programs, football in particular, affect the diversity of student enrollment. The study's findings also have implications for future research. While the current study supported the fact that adding a new football program helped small, private college diversify their campuses, the study did not account for the long-term diversification of small, private college campuses. Longitudinal research should be conducted to determine if the addition a new football program, or any college sport, has lasting effects on the diversity of small, private college campuses. The current study only examined small, private college with enrollments of 2,500 students or less. To make a more definitive statement on the impact of adding a new football program on college campuses, research must also examine private college campuses with enrollment of more than 2500 students and at large public universities.

While the current study supports the hypothesis that adding a new football program will help small, private institutions diversify their campuses, there is a need to understand how the 
diversification of a small, college campus affects the culture of campus. As stated in the literature review, small, private colleges have traditionally lacked males and minority students on campus. The addition of a new football program will instantly add a significant number of male and minority students on campus, thus potentially altering the current campus culture. University and sport leaders must be ready to cope with and address the expected changes from bringing such a large group of students to campus at one time.

\section{Limitations}

A limitation of the current study is the time frame used for the analysis. The 50 institutions that served as the main research group all started new football programs and are representative of the 1990-2013 timeframe. However, the comparison groups, institutions that had existing football programs and institutions without football programs, were only analyzed in reference to the 2006 benchmark year. The data used for these groups were only representative of the years from 20032008, thus leaving out a large portion of the 1990-2013 timeframe. While the results of the study are credible for the 2006 benchmark, the study could be improved by analyzing data from multiple years within the study timeframe. A second weakness of the study is that it does not account for other factors that could affect enrollment at small, private institutions. While the literature is very clear that university and sport leaders at small, private institutions believed that adding a new football program could have the greatest potential impact of student enrollment, there is no guarantee that other factors did not influence some of the changes in diversity of student enrollment.

\section{Recommendations for Future Research}

The findings from the current study provide a unique contribution to the knowledge of how adding a new football program affects a small, private university. The current study also exposes gaps in the knowledge surrounding the topic and provides some unique opportunities for future studies. There is a great need for a qualitative study on the impact of a college football program on the diversity of a campus. The quantitative data provides evidence that starting a new a football program on a small, college campus will increase the diversity enrollment. However, there is a need to hear the stories of various stakeholders on the campuses that have started new football programs. A qualitative study will provide narratives on how administrators, students, staff, and community members viewed the addition of a new football program. In addition, narrative data will provide a list of the positive and negative impacts felt by those living and working on a campus that added a new football program. Small, private universities, like all higher education institutions, spend considerable time and effort improving student retention and graduation rates. The addition of new athletic programs, football in particular, will have an impact on the retention and graduation rates at a small, private institution. A study is needed that examines how the addition of a new football program on a small, private campus affects the retention and graduation rates of the institution. A further step in advancing this line of research is to acquire qualitative data on the lived experiences of stakeholders on small, private college campuses that have added new football programs and to examine how adding a new football program affects the retention and graduation rates of small, private institutions. 


\section{Conclusion}

The purpose of the current study was to explore if the addition of a new football program on small, private college campuses resulted in an increase in minority and male student enrollments. This study found that the addition of a new football program on small, private college campuses resulted in increases in minority and male student enrollment compared to campuses that already had football programs or campuses that did not launch such a program. The current study is significant because it shows that by adding a new football program, small private institutions can balance their enrollment of males and females and provide minority students with an opportunity to earn a college education. While the addition of a new football program can help small, private institutions address some of their enrollment shortcomings, higher education and sport leaders must do everything in their power to ensure the success of the potential new college students brought to campus through the addition of a new football program. The current study's findings add to the existing knowledge base on how the addition of a new football program affects a small, private college campus and provides unique data that is valuable to university and sport leaders. 


\section{References}

Aguirre, A., \& Martinez, R. (2002). Leadership practices and diversity in higher education: Transitional and transformational frameworks. Journal of Leadership Studies, 8(3), 5362. doi:10.1177/107179190200800305

Bandre, M. A. (2011). The impact of financial aid on the enrollment and retention of student athletes at National Collegiate Athletic Association (NCAA) division III colleges and universities: A review of literature. Journal of Student Financial Aid, 41(1), 38-45.

Beamon, K. (2014). Racism and stereotyping on campus: Experiences of African American males' student-athletes. The Journal of Negro Education, 83(2), 121-132.

Beaver, W. (2014). The changing nature of division III athletics. College and University, 89(3), $32-40$.

Belli, G. (2009). Nonexperimental quantitative research. In S. D. Lapan \& M. T. Quartaroli (Eds.), Research essentials: An introduction to designs and practices (pp. 59-77). JosseyBass.

Black, J. (2001). Strategic enrollment management revolution. Annapolis Junction: AACRAO.

Blackhurst, A. E., \& Auger, R. W. (2008). Precursors to the gender gap in college enrollment: Children's aspirations and expectations for their futures. Professional School Counseling, 11(3), 149-158.

Bowman, N. A. (2013). How much diversity is enough? The curvilinear relationship between college diversity interactions and first-year student outcomes. Research in Higher Education, 54(8), 874-894.

Breneman, D. W. (1994). Liberal arts colleges: Thriving, surviving, or endangered. Brookings Institute.

Butler, J. E. (2000). Democracy, diversity, and civic engagement. Academe, 86(4), 52-55.

Caro, C.A. (2014). Quantifying the chasm: Exploring the impact of the BCS on total football revenues for division one programs from 2002-2012. Contemporary Issues in Education Research, 7(3), 39-49.

Casciaro, T., \& Piskorski, M. J. (2005). Power imbalance, mutual dependence, and constraint absorption: A closer look at resource dependency theory. Administrative Science Quarterly, 50(2), 167-199. 
Godfrey, R. D. (2009). Giving a voice to black and Latino men: First-year student's perceptions of the relative impact of family support and college aspirations on their decisions to enroll and actual college enrollment (Publication No. 3349653) [Doctoral dissertation, Boston College]. https://dlib.bc.edu/islandora/object/bcir:10126420170512120342926558733

D3 Football. (2017). Division III team names, schedules, and results. http://www.d3football.com/teams/index

Dalton, B. F. (2011). Enrollment and fiscal health of small, tuition-dependent private colleges with new football programs [Unpublished doctoral dissertation]. University of Texas at Austin. UT Electronic Theses and Dissertations.

Dalton, B., \& Somers, P. (2015). The "Hail Mary" touchdown: A study of how football became an enrollment management strategy for small, private colleges. Strategic Enrollment Management Quarterly, 2, 294-306. https://doi.org/10.1002/sem3.20054

Davis, J. (2011). The pigskin and the cross: Intercollegiate football on the faith-based campus (Publication No. 3491223) [Doctoral dissertation, Indiana State University]. ProQuest Dissertations.

Dimaria, J., \& Pullano, L. (2004). Using athletics to win the enrollment game. SEM Source. January. Available at: www4.aacrao.org.org/sem-source/sem/index5b9e.html.

Dosh, K. (2013). Saturday Millionaires. Wiley.

Ensign, J., \& Woods, A. M. (2014). Strategies for increasing academic achievement in higher education. Journal of Physical Education and Dance, 85(6), 17-22.

Feezell, T. (2009). Adding football and the "uses" of athletics at NCAA division II and III institutions. New Directions in Higher Education, 148, 65-72.

Fine, E., \& Handelsman, J. (2010). Benefits and challenges of diversity (2nd ed.). Board of Regents of the University of Wisconsin System.

Gardiner, A. (2010, August 11). Schools find football programs spur buzz, campus growth. USA Today. http://usatoday30.usatoday.com/sports/college/football/2010-08-11-footballspurs-buzz-growth_N.htm

Gatmen, E. J. P. (2011). Academic exploitation: The adverse impact of college athletics on educational success of minority student-athletes. Seattle Journal of Social Justice, 10(1), 509-583.

Getz, M., \& Siegfried, J. (2012). College sports: The mystery of the zero-sum game. Change, 5259. 
Ginder, S. A., Kelly-Reid, J. E., \& Mann, F. B. (2016). Integrated Postsecondary Education Data Systems (IPEDS) Methodology Report (NCES 2016-111). National Center for Education Statistics.

Goodman, K. M., \& Bowman, N. A. (2014). Making diversity work to improve college student learning. New Directions for Student Services, 147, 37-48.

Hackett, C. D., \& Sheridan, D. A. (2013). Predictors of commitment to graduation: African American male student athletes in California community college systems. Journal of Applied Research in Community College, 20(2), 37-52.

Harber, S. R. (2009). Race, interest convergence, and transfer outcomes for Black male student athletes. New Directions for Community Colleges, 147, 29-37.

Hardwick-Day. (2008, January). NCAA division II values study. Indianapolis, IN: NCAA. https://www.ncaa.org/sites/default/files/NCAA_DII_Values_Study_Jan_2008.pdf?division=d2

Haring-Smith, T. (2012). Broadening our definition of diversity. Liberal Education, 98(2), 6-13.

Harper, S. R., Williams, C. D., \& Blackman, H. W. (2013). Black male student-athletes and racial inequities in NCAA Division I college sports. Center for the Study of Race and Equity in Education.

Hossler, D., \& Kalsbeek, D. (2008). Enrollment management and managing enrollment: Setting the context for dialogue. College and University, 83(4), 3-9.

Huffman, A. C. (2013). A description and comparison of the perceptions of NCAA division II and division III college presidents regarding the impacts of intercollegiate athletics at their institutions (Publication No. 3576290) [Doctoral dissertation, West Virginia University]. ProQuest Dissertations.

Huggins, E. (2015). Through their eyes: Understanding factors critical to the academic success of African American males (Publication No. 3684589) [Doctoral dissertation, Northcentral University]. ProQuest Dissertations.

Kelley, D., \& Dixon, M. A. (2011). The strategic benefits of adding football for NCAA division I institutions. Journal of Intercollegiate Sport, 4, 283-303.

Lammers, J. (2010, April 11). Lake Erie College gets boost from athletics. The News- Herald. https://www.news-herald.com/news/lake-erie-college-gets-boost-from-athleticsvideo/article_45ad1b54-8f39-504c-9de3-594248d3a2f2.html

Locke, J. D. (2010). The influence of sports participation on the identity development of African American males (Publication No. 3481725) [Doctoral dissertation, John F. Kennedy University). ProQuest Dissertations. 
Lynch, M. (2015, May 28). How do we get more Black men to attend college? Education Week. http://blogs.edweek.org/edweek/education_futures/2015/05/how_do_we_get_more_black _men_to_attend_college.html

McCloskey Jr., J. R. (2016). Campus culture effects from adding football at NCAA division I institutions [Unpublished doctoral dissertation]. Wilmington University.

Moltz, D. (2009). Academic accountability in athletics. Inside Higher Education. https://www.insidehighered.com/news/2009/03/09/academic-accountability-athletics

National Association of Intercollegiate Athletics. (2016). About the NAIA. https://www.naia.org/membership/2015-16/releases/20160411bcnqp

National Association of Intercollegiate Athletics. (2017). NAIA member school directory. https://www.naia.org/schools/index

National Center for Educational Statistics. (2017a). IPEDS. https://nces.ed.gov/ipeds/Home/UseTheData

National Center for Educational Statistics. (2017b). Overview of IPEDS data. https://nces.ed.gov/ipeds/InsidePages/UseTheData?pageid=58

National Collegiate Athletic Association. (2016a). What is the NCAA? http://www.ncaa.org/about/resources/media-center/ncaa-101/what-ncaa

National Collegiate Athletic Association. (2016b). Our three divisions. http://www.ncaa.org/about/resources/media-center/ncaa-101/our-three-divisions

National Collegiate Athletic Association. (2017). NCAA best practices: Achieving excellence through diversity and inclusion. http://fs.ncaa.org/Docs/AMA/Athletics\%20Cert/Achieving\%20Excellence.pdf

National Collegiate Athletic Association. (2017). NCAA division III membership. http://www.ncaa.org/governance/membership?division=d3

National Collegiate Athletic Association. (2014). Added and discontinued programs. http://fs.ncaa.org/Docs/stats/football_records/2014/programs.pdf

National Football Foundation. (2018, July 28). Colleges and universities offering football increases to all-time high of 778. https://footballfoundation.org/news/2018/6/28/record778-colleges-and-universities-now-offering-football.aspx?path=football

Pennington, B. (2006, July 10). Small college, short of men, embrace football. New York Times. https://www.nytimes.com/2006/07/10/education/10football.html 
Pfeffer, J., \& Salancik, G. R. (2003). The external control of organizations: A resource dependence perspective (Rev. ed.), Stanford University Press.

Rea, L. M., \& Parker, R. A. (1992). Designing and conducting survey research a comprehensive guide. Jossey-Bass. Sage, G. H., \& Eitzen, D. S. (2016). Sociology of North American sport (10th ed.). Oxford University Press.

Salkind, N. J. (2014). Statistics for people who think they hate statistics (5th ed.). Sage. Schulz, S. A., \& Lucido, J. A. (2011). What enrollment management structures reveal about institutional priorities. Enrollment Management Journal, 5(4), 12-44.

Sports Business Research Network. (2016). Football participation analytics. http://www.sbrnetportal.com/Analytics.aspx

Stern, G. M. (2011). How is the economy affecting private college enrollment? The Hispanic Outlook in Higher Education, 21(7), 12-13.

Suggs, W. (2004). Making the varsity: College sports and institutional choices. Chronicle of Higher Education, 59-61.

Talmadge, R. A. (2014). Campus diversity and perspective-changing: Students describe the impact of their interactions with diverse peers and viewpoints (Publication No. 3614922) [Doctoral dissertation, Fielding Graduate University]. ProQuest Dissertations.

Thomas, I., \& Nasir, N. S. (2013, May 7). Black males, athletes and academic achievement. Huffington Post. http://www.huffingtonpost.com/isiah-thomas/black-males-athletes-and_b_3232989.html

Van Holm, E. J., \& Zook, S. (2016, February 17). Returns for a touchdown? Universities entering college football. SSRN: https://ssrn.com/abstract=2733761

Vanover, E. J., \& DeBowes, M. M. (2013). The impact of intercollegiate athletics in higher education. Academic Perspectives in Higher Education Journal, 1(1), 40-63.

Wang, W., \& Parker, K. (2011, August 17). Women see value and benefits of college: Men lag on both fronts, survey finds. Pew Research Center. http://www.pewsocialtrends.org/2011/08/17/women-see-value-and-benefits-of-college-menlag-on-both-fronts-survey-finds/

Weatherall, M. P. (2006). How NCAA division III colleges and universities use athletics as part of their strategic enrollment management plan: A case study of three institutions. (Publication No. 3209999) [Doctoral dissertation, University of Pennsylvania]. ProQuest Dissertations. Weaver-Hightower, M. B. (2010). Where the guys are: Males in higher education. Change, 42(3), 29-35.

Wilson, J. L. (2015). Presidential plans: New college presidents and diversity efforts. Planning for Higher Education Journal, 44(1), 76-86. 
